\title{
REGENERATION OF THE LOWER FEMORAL EPIPHYSIS
}

\section{Report of a Case}

\author{
R. McKiellar Hall, Perth, Western Australia
}

This case is considered to be of interest because, after a lapse of at least four years since its destruction, the medial condylar part of the lower femoral epiphysis appears to be regenerating. The patient had suffered from suppurative arthritis of the knee joint with cpiphysitis of the femur at the age of three weeks, resulting in complete destruction of the medial condylar part of the epiphysis (Fig. 1).

He was first referred to me, when he was ten and a half months old, because of increasing genu varum. The previous history was that at the age of three weeks pus containing staphylococcus aureus was aspirated from the distended, painful knee and replaced with a corresponding amount of sterile normal saline containing $\mathbf{4 0 , 0 0 0}$ units of penicillin. Plaster and light traction were applied. Administration of penicillin was continued both by daily replacement for twelve days and parenterally for the same twelve days and another four. sulphadiazine was given from the ninth to the eighteenth day.

The genu valgum was treated at first with a Thomas's bed knee splint and, after four months, with a Thomas's caliper. A year later it was doubtful whether there had been any improvement. The patella was lying over the lateral condyle and slipped medially on flexion

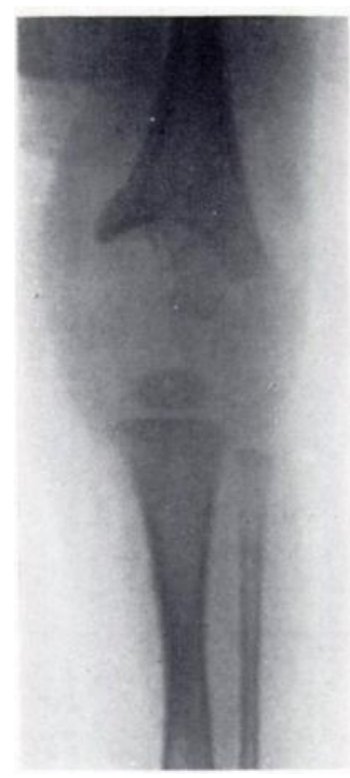

Fig. 1

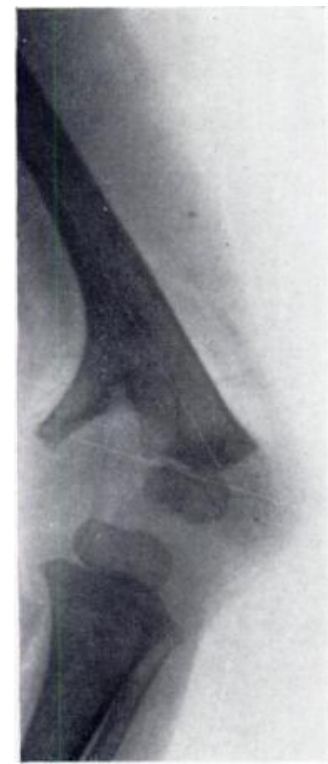

FIG. 2

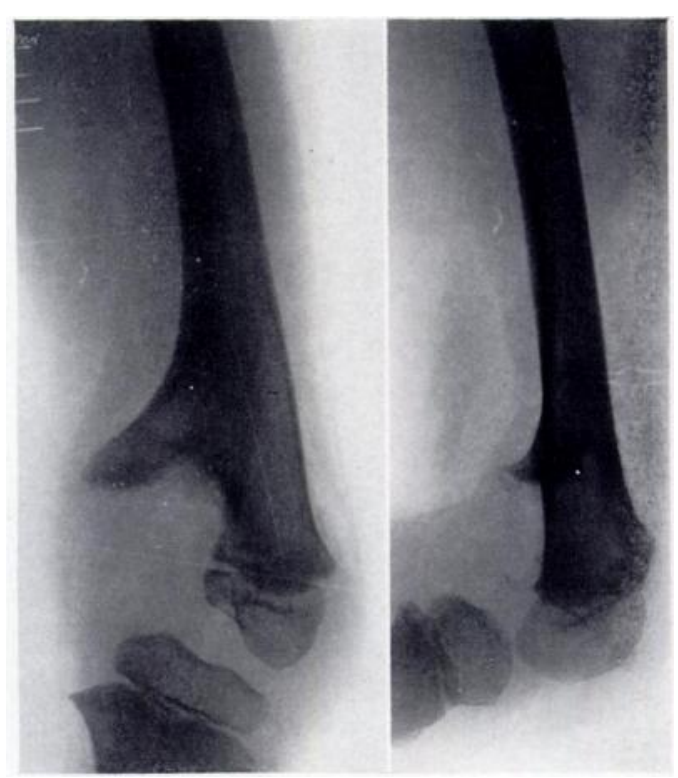

FIG. 3

Figure 1--Farly radiograph three months after onset of suppurative arthritis and epiphysitis. Figure 2 One year later. Figure 3-Four years later.

of the joint. After a further year the patella no longer slipped sideways. The leg was one and three-quarters inches short. Three years after his first attendance the clinical condition was the same. There was no increase in the bowing, but no apparent growth in the medial condyle. The radiographs (Fig. 3) showed what might be regarded, in the light of subsequent progress, 
as commencing regeneration of the epiphysis on the medial condyle; and the angle of the epiphysial line on the lateral condyle had improved from a varus angle of about 45 degrees to one of 20 degrees.

The patient was last examined seven years after his first attendance. The knee was

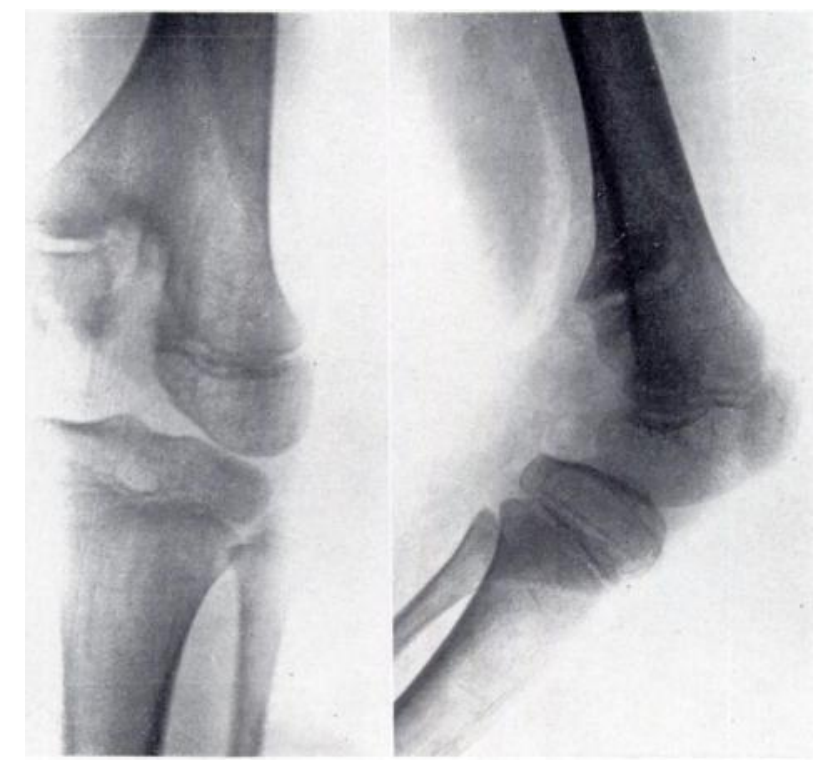

Fig. 4

Condition seven years after onset, showing partial regeneration of the medial femoral condyle.

then stable and straight; the range of flexion was about 70 degrees. During movement a click was felt over the prominent lateral condyle, and the patella was felt to hide in the gap where the medial condyle of the femur should be. The limb was about two inches short. The clinical impression was that the medial condyle was redeveloping. Radiographs (Fig. 4) confirmed this. 